\title{
How universities can work together with local communities to create a green, sustainable future
}

\author{
Yuhlong Oliver $\mathrm{Su}^{1 *}, \mathrm{Ku}$-Fan Chen ${ }^{2,3}$, Yung-Pin Tsai ${ }^{2,3}$, and Hui-I $\mathrm{Su}^{3}$ \\ ${ }^{1}$ Office of President, National Chi Nan University, 1 University Road, Puli, Nantou 54561, Taiwan, ROC \\ ${ }^{2}$ Department of Civil Engineering, National Chi Nan University, 1 University Road, Puli, Nantou 54561, Taiwan, ROC \\ ${ }^{3}$ Environmental Protection and Occupational Safety and Health Center, National Chi Nan University, 1 University Road, Puli, \\ Nantou 54561, Taiwan, ROC
}

\begin{abstract}
Over the past few years, National Chi Nan University (NCNU) has made significant achievements in its development as a "green university." Besides continuing to implement sustainable development of its campus, NCNU has also been implementing the "Citizenship Cultivation Plan," "University without Boundary Project" and "University Social Responsibility (USR) Plan," using the local community as a test-bed, and working actively to integrate NCNU's curriculum with the community, so as to enhance awareness of local environmental issues among students, faculty members and local residents, and build consensus of sustainable environmental development. NCNU has implemented a range of action plans and practical courses of environmental education to work together with local residents for environmental issues, such as water resources, air quality, waste, etc. Through these activities, NCNU's students and faculty members and local residents are able to develop a better understanding of the environment, and how they can make a bigger contribution towards environmental protection. Regarding the international voluntary service activities, NCNU has endeavored to fulfil its social responsibility as a university. Under the dynamic leadership of President Dr. Yuh-Long Su, College of Science and Technology and College of Management have joined forces with "Chunghwa International Sunshine Charitable Association" established by Taiwanese businesspeople in Southeast Asia, using NCNU's knowhow and technology to build the water purification systems in Cambodia, providing clean and safe drinking water for people in remote and disadvantaged areas. NCNU has strongly rooted in the local community with the content of the United Nations' Sustainable Development Goals (SDGs) to build capabilities in four key areas - educational development, local action, industry-academia collaboration, and global integration - and to expand the scope of its activities from the local to the international. In the future, NCNU will continue devoting itself to sustainability and environmental issues, working wholeheartedly to meet its social responsibility goals as a university.
\end{abstract}

\section{A Vision of Transforming National Chi Nan University into a Green University}

To effectively implement the vision of being a green university, National Chi Nan University (NCNU) has adopted a campus plan which incorporates ecological principles and environmental protection measures into the university's operations management, thus fostering an ecologically diverse campus and a more sustainable living environment [1] [2]. Academic and administrative units work together to encourage relevant research, clubbased activities, and promotional activities and combine these efforts with three major programs (civic development, university without boundary, and university social responsibility (USR)) to enhance the scope and comprehensiveness of courses that involve sustainable development education. In addition to encouraging faculty and students to get involved in the community, the concepts of sustainable development and environmental protection are integrated into the university's core educational mission to construct a learning environment which integrates pedagogical knowledge and community life and provides opportunities for practical, hands-on participation [3] [4]. By focusing on potential problems and needs within the community and bringing attention to production, lifestyle, and ecological issues that impact local residents, we can more readily understand the tenets of sustainable development. To date, NCNU students and faculty have established a long-term presence in six communities to carry out local engagement and develop action plans for issues that impact the local community, such as eco-towns, social welfare, green economy, cultural revitalization, and civic engagement. Students also team up with local residents to find and implement solutions to sustainability issues, gathering new momentum for community development. NCNU's vision for achieving sustainable development also combines local characteristics with the sustainable development goals (SDGs) formulated by the United Nations [5]. This vision also considers social welfare service providers, friendly environment participants, sustainable

\footnotetext{
* Corresponding author: yosu@ncnu.edu.tw
} 
development educators, community development leaders, and corporate social responsibility achievers to be the main pillars of sustainable development planning and implementation, as illustrated in (Fig; 1. NCNU has developed a four-pronged approach consisting of educational development, local action, industry- academia cooperation, and global integration (Fig 2) and is continuing to make a concerted effort on issues relating to environmental sustainability in order to help prepare students to become modern citizens who have the wherewithal to care for society and gainfully participate in public life.

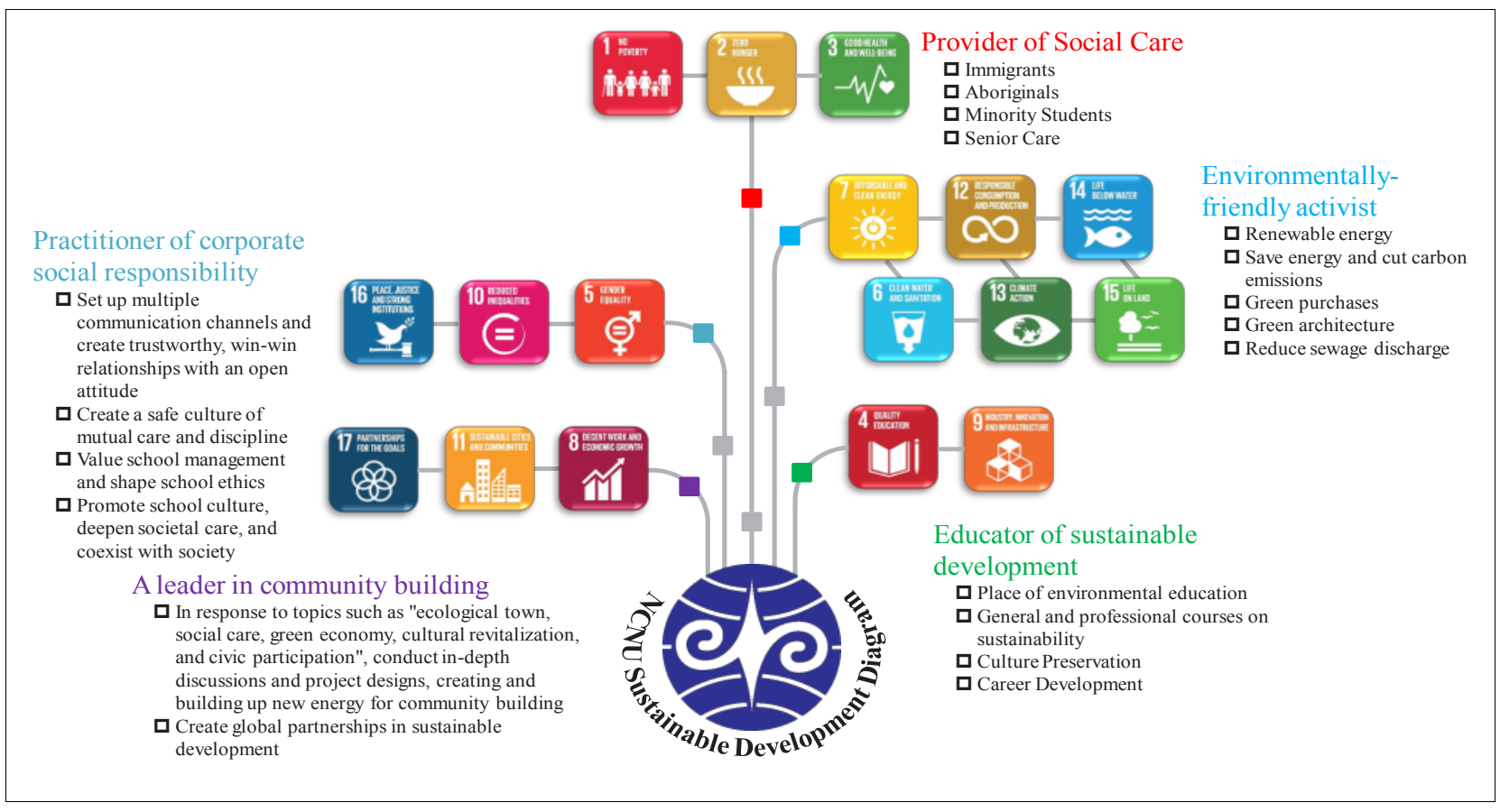

Fig. 1. Diagram showcasing NCNU's vision for sustainable development.

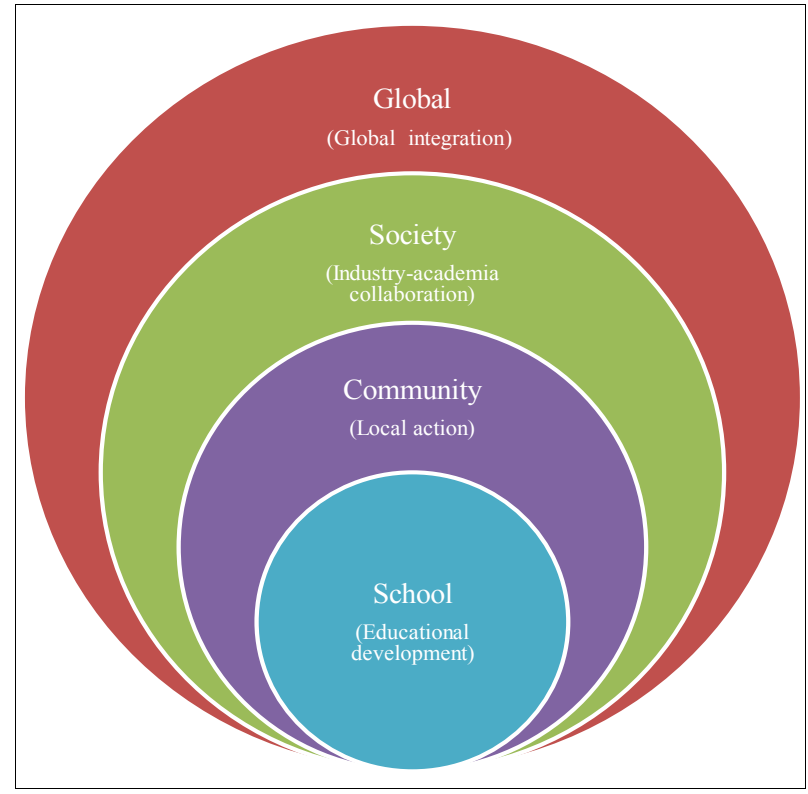

Fig. 2. Blueprint of NCNU's sustainable development from local to global implementation.

\section{Cultivating civic awareness through an open and engaging university}

NCNU strives to instill civic consciousness in students by enabling the university's faculty and students to partner up with local residents. NCNU applies the university's knowledge and specialized competencies in domains ranging from ecology and production to life and culture, lending assistance on local governance and facilitating development which is mutually beneficial to the university and local community, as well as taking time to reflect on progress made during the implementation process to devise more diverse learning pathways for the future, as illustrated in (Fig. 3). 
Methods for implementing the civic development program are contingent on the following: 1 . Collaborative learning and sharing: Aims to form a collaborative learning environment and atmosphere for students, faculty, and local residents in a way that facilitates sharing and experience exchange among participants, thereby promoting action and continuous advancement. 2. Community outreach: The university teams up with the community to raise questions, discuss opinions, and work together to conceptualize objectives and content of action plans, integrate resources, and delegate tasks. 3. Curriculum innovation: University faculty are encouraged to utilize diverse educational methods and place an emphasis on the learning content and learning quality of students by making reforms and adjustments to the curriculum. Experience sharing through teacher networks enables educators to learn from each other and motivate one another. 4. Student support system: Students are accompanied and encouraged to form interdisciplinary teams and examine real issues in life, propose solutions, hold practical consultations, and exchange opinions and feedback. 5. Living labs: Students, faculty, and people in the local community are inspired to have greater awareness of real issues and implement five strategies, including experimentation, which apply social innovation perspectives in the real world.

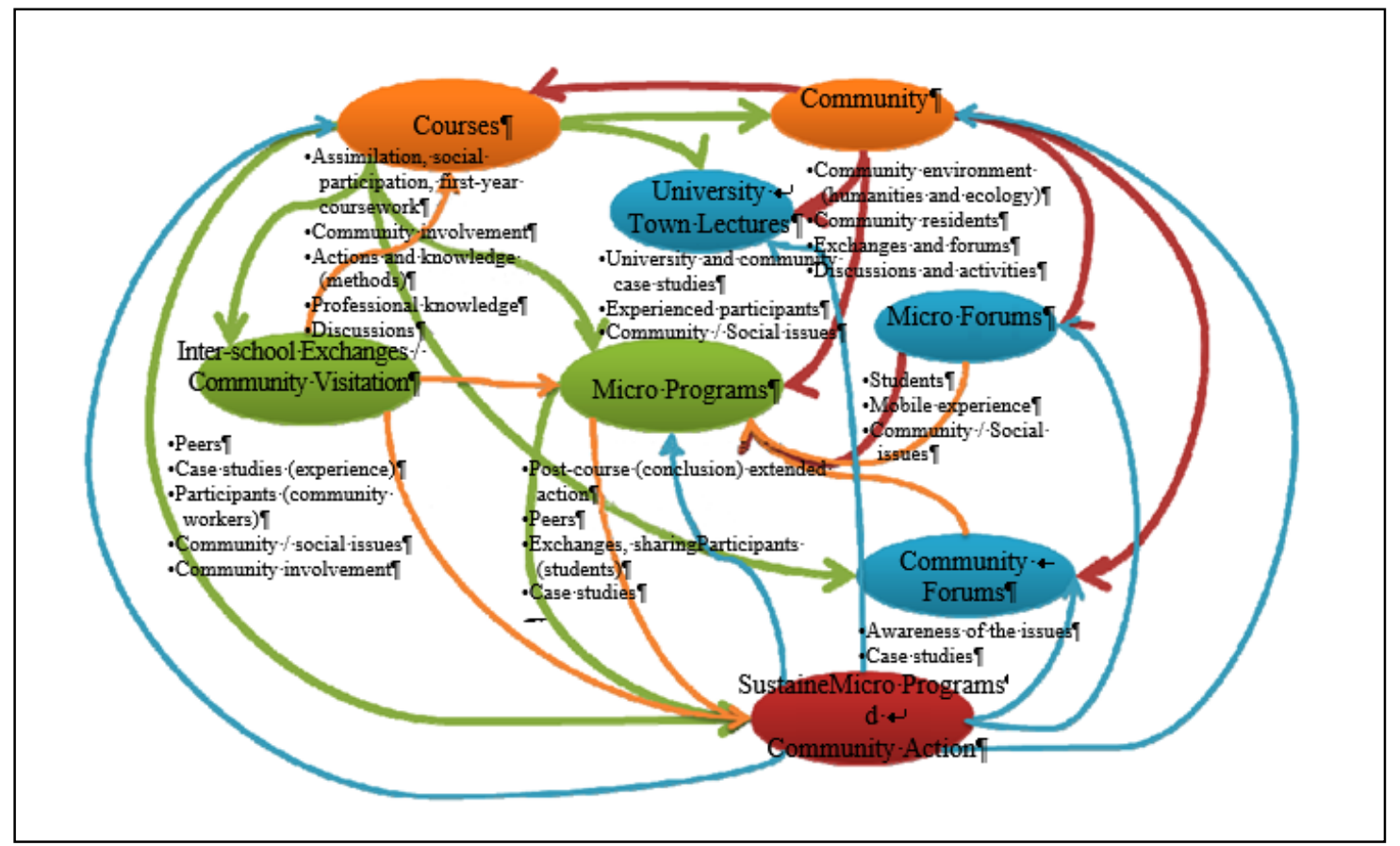

Fig. 3. Participation-based learning environment avenues of diverse learning.

\section{Developing new talent by breaking down barriers to learning}

NCNU utilizes four approaches, namely collaborative learning, collaborative education, local symbiosis, and collaborative creation, and achieves implementation through various programs. Various action plans allow these four approaches to be mutually supportive of each other, as illustrated in (Fig. 4). Various learning resources from within and without the university are linked together, including diverse types of educational labs, workshops, learning sites, and regional collaborative locations both inside and outside of the university. Meanwhile, integrate relevant resources within the university relating to social participation, expand and elevate organizational competencies, and jointly develop and cultivate young talent with practical abilities who can remain or return home.

The university without boundary program aims to achieve four goals: 1 . Help educated youths cultivate the ability to return home and transform learning methods in a way that enables the university to become an incubator for developing talent who pay attention to urban and rural issues and strive for innovative development. 2 . Foster a collaborative learning and working environment for NCNU and the local community, provide systematic support to methodically expand and develop the learning field, allow the university to forge closer ties with the local community, and achieve synergy between university and local knowledge in a way that is mutually useful and supportive. 3. Design a "learning without barriers" model for NCNU and the local community which includes promotional activities, invention showcases, interactive platforms, and other approaches to break away from formulaic curriculum barriers relating to space, time, subjects, and relationships and overhaul existing learning methods. 4. Facilitate change in NCNU's learning ecosystem via cross-unit and crosslevel integration to establish an institutional support framework that provides an impetus for changing interdisciplinary collaboration, thereby progressively transforming the university's learning ecosystem. 


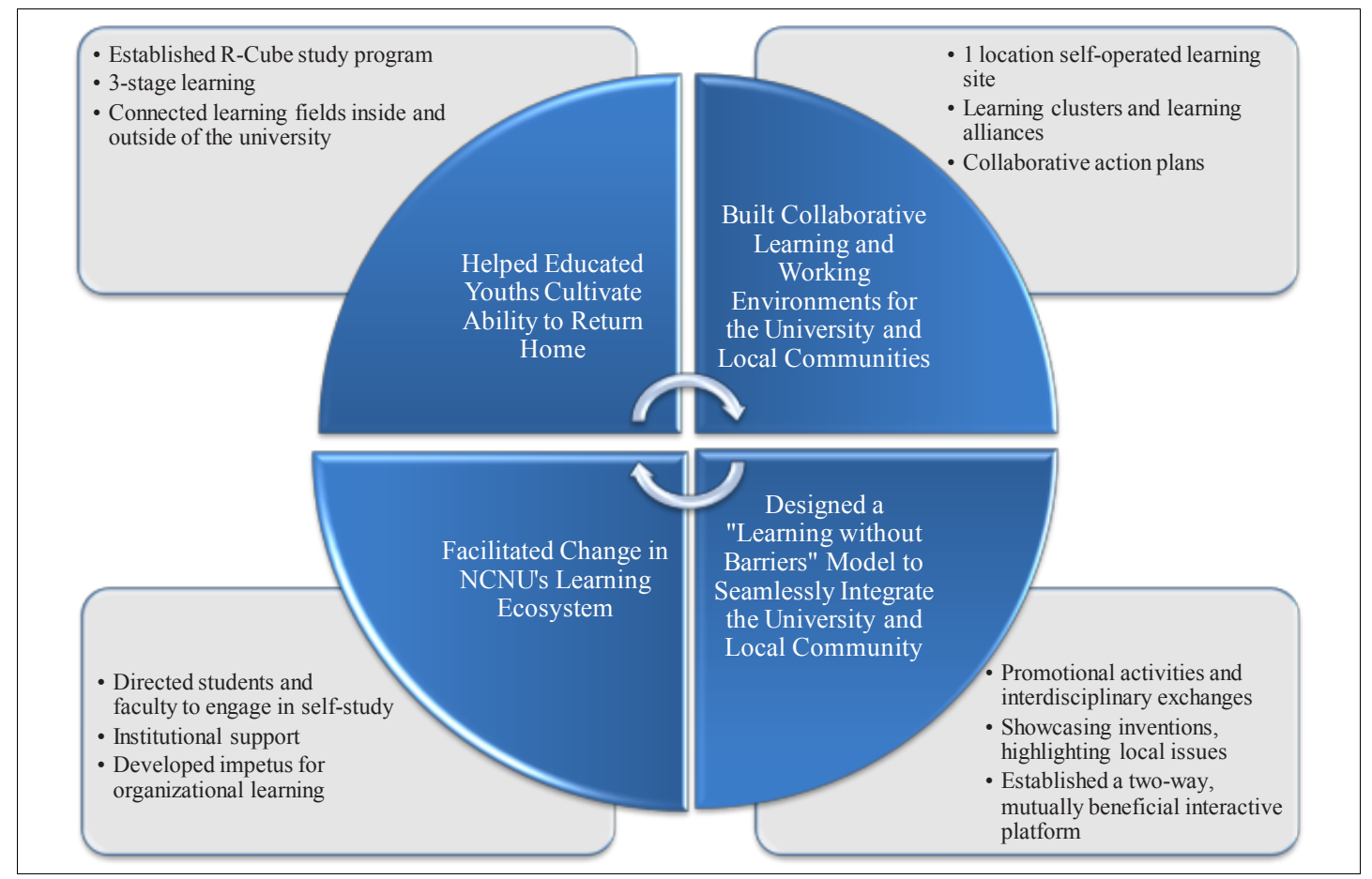

Fig. 4. Transforming NCNU's learning ecosystem.

\section{Fulfilling university responsibility and increasing outreach experience}

NCNU fulfills university social responsibility [6], allows faculty and students to embrace their vitality, aids in regional development, solve difficult local problems, and utilize technology to effectively promote the welfare of the general public. One of the most eagerly talked about achievements is the "PM 2.5 Team", which is comprised of NCNU students and faculty who developed a "PM 2.5 micro detector". The device is capable of transmitting monitoring data to the university's cloud platform via Wi-Fi and Bluetooth. The records, calculations, and analysis derived from the data allow changes in air quality in Puli Township to be ascertained with high precision. Data displayed by the monitoring device can generate greater alertness and gradually change public habits, thus resulting in self-perpetuating education. Currently, NCNU students and faculty are also providing assistance to Taumi Eco-village, located nearby the university, to construct artificial wetlands for treating wastewater discharged by the site's guest houses as well as to install smart utility meters which will help meet the energy-saving needs of the guest houses.

Over the years, NCNU has made substantial accomplishments owing to its participation in community development. The university has established an interdisciplinary teacher network for holding practical discussions which is staffed by 47 local practice faculty members (accounting for approximately $1 / 6$ of the university's total faculty), and each academic year 1,222 students (accounting for about $1 / 5$ of the total student body) participate in social practice courses, including the development of 44 research topics pertaining to social practice and collaboration with 7 government departments, and a total of 39 student and faculty clubs have also taken action locally, the effects of which are illustrated in Fig. 5.

\section{Thinking globally and acting locally to connect local communities with the world}

As the only national public university in Nantou County, NCNU is playing an important role in providing assistance on regional development in Nantou County, thereby fulfilling its function as a local storehouse of knowledge and promoting development through "university-led local collaborative governance" and "locally-led university ecosystem innovation". NCNU endeavors to fulfill its university social responsibility by providing services on that impact other parts of the world. Under the leadership of NCNU President Dr. Yuh-Long $\mathrm{Su}$, a global volunteer team created by the university's College of Science and Technology and the College of Management has teamed up with Taiwanese businesses in Cambodia to provide knowledge and technology to build water treatment systems in rural communities that provide a safe source of drinking water. In the future, NCNU will also engage in global crowdfunding efforts to build more water treatment facilities that benefit rural residents in Cambodia, highlighting that Taiwan is committed to doing its part as a global citizen to help others. 


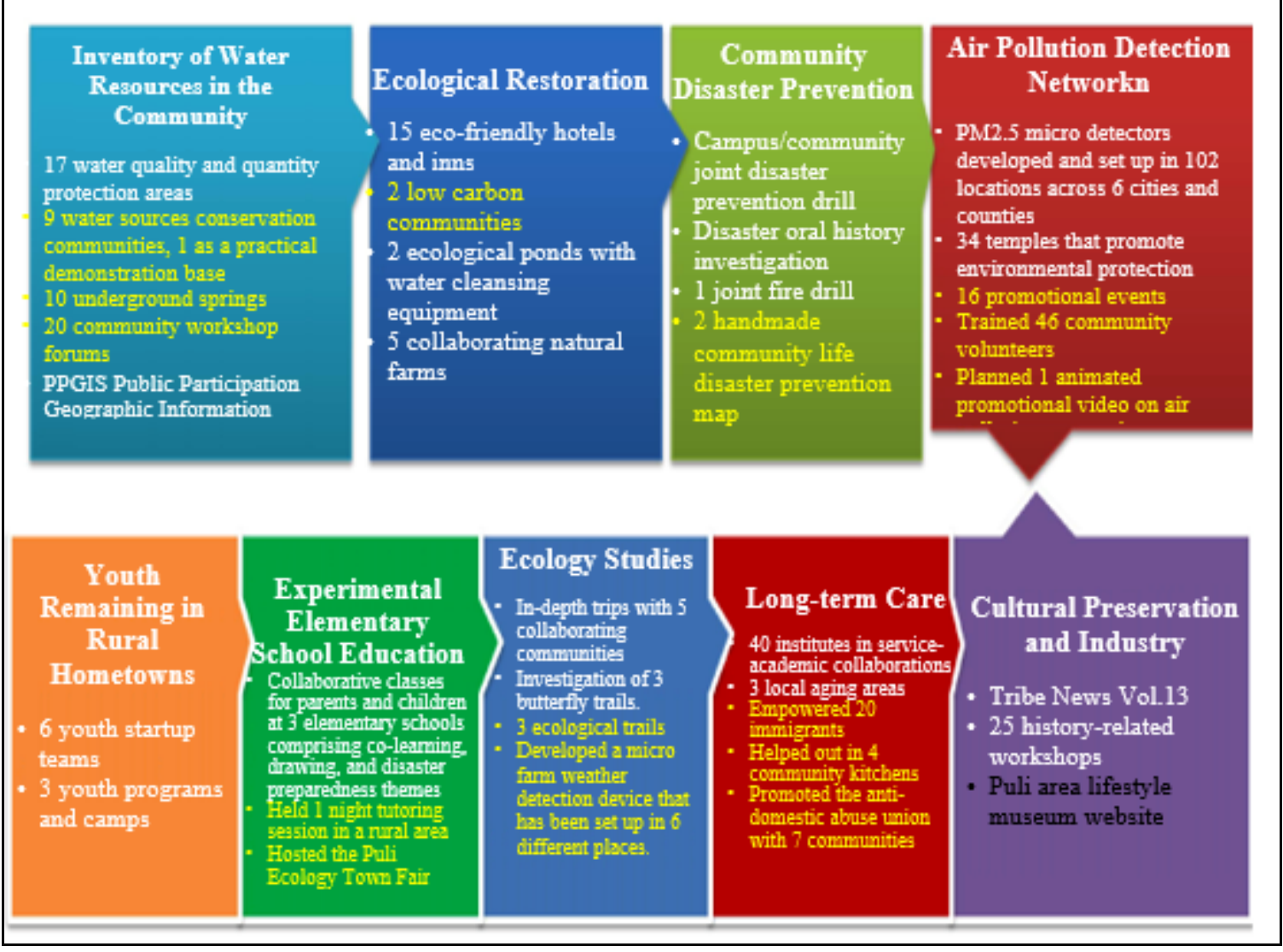

Fig. 5. Illustration showing involvement of National Chi Nan University in social practice projects and their effects from 2013 to the present.

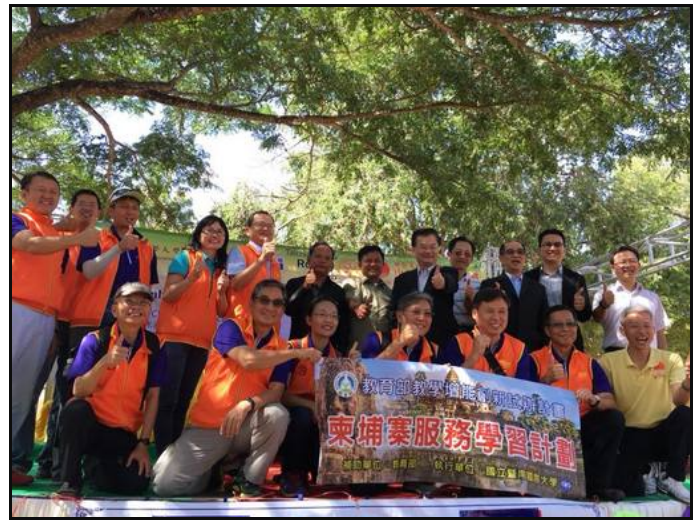

Fig. 6. By lending assistance to people in Cambodia, NCNU is fulfilling its university social responsibility (USR).

\section{Conclusion}

NCNU is committed to fulfilling its university social responsibility and thoroughly incorporating the concept of environmental sustainability into coursework and campus life. NCNU will furthermore continue to embrace a vision of making positive impacts on local elementary and junior high schools, local communities, and society at large while becoming increasingly connected with the world. As an academic institution, NCNU also plays a part in ensuring the stable operation of society, the economy, and protecting the environment of our communities, and thus has an obligation to lead society toward sustainable development. With respect to environmental issues, humanity is at a crossroads, and environmental education is paramount; this is why NCNU developed a four-pronged approach educational development, local action, industryacademia cooperation, and global integration — based on the school's local characteristics and the UN's sustainable development goals (SDGs). Going forward, NCNU will continue to think globally and act locally, make a concerted effort on issues relating to environmental sustainability, and strive to fulfill its duties as a socially responsible university.

\section{References}

1. Su, Y.O., Liu, I.C., Chen, K.F., Chang, Y.T., Green NCNU in The Heart of Taiwan. The 3rd International Workshop on UI GreenMetric, April 10-11, Istanbul, Turkey (2017)

2. Lauder, A., Sari, R.F., Suwartha, N., Tjahjono, G., 2015. Critical Review of a Global Campus Sustainability Ranking: GreenMetric. Journal of Cleaner Production, 108, Part A, pp. 852-863.

3. Suwartha, N., Sari, R.F., Evaluating UI GreenMetric as a Tool to Support Green Universities Development: Assessment of the Year 2011 Ranking, 61, pp. 46-53 (2013)

4. Delanty, G., Challenging Knowledge: The University in the Knowledge Society. Bukingham: Open University Press., (2001) 
5. UNESCO (United Nations Educational, Scientific and Cultural Organization), Education for Sustainable Development Goals: Learning Objectives. ISBN 978-92-3-100209-0, Paris, France (2017)
6. López, S.G., Benítez, J.L.S., Sánchez, J.M.A., Social Knowledge Management from the Social Responsibility of the University for the Promotion of Sustainable Development. Procedia- Social and Behavioral Sciences, 191, pp. 2112-2116 (2015) 